\title{
Comprehensive investigation of Pd/ZSM-5/MCM-48 composite catalysts with enhanced activity and stability for benzene oxidation
}

\author{
Chi He ${ }^{a}$, Jinjun $\mathrm{Li}^{\mathrm{a}}$, Peng $\mathrm{Li}^{\mathrm{a}}$, Jie Cheng ${ }^{\mathrm{a}}$, Zhengping Hao ${ }^{\mathrm{a}, *}$, Zhi-Ping Xu ${ }^{\mathrm{b}, * *}$ \\ a Department of Environmental Nano-materials, Research Center for Eco-Environmental Sciences, Chinese Academy of Sciences, Beijing 100085, PR China \\ ${ }^{\mathrm{b}}$ Australian Research Council (ARC) Centre of Excellence for Functional Nano-materials, Australian Institute for Bioengineering and Nanotechnology \\ and School of Engineering, The University of Queensland, Brisbane, QLD 4072, Australia
}

\section{A R T I C L E I N F O}

\section{Article history:}

Received 31 October 2009

Received in revised form 26 February 2010

Accepted 2 March 2010

Available online 9 March 2010

\section{Keywords:}

Two-step crystallization

ZSM-5/MCM-48

Acidity

Stability

VOCs

\begin{abstract}
A B S T R A C T
ZSM-5/MCM-48 composite materials with various acidities have been successfully assembled on zeolite seeds via a two-step crystallization process. The characterization results reveal that the ZSM-5 seeds are present in the framework of the resulting composite materials with its content gradually increasing with the $\mathrm{Si} / \mathrm{Al}$ molar ratio, and $\mathrm{Al}$ atoms prefer the tetrahedral coordination in composite products. The amount of strong acid sites increases as the $\mathrm{Si} / \mathrm{Al}$ molar ratio decreases, while that of weak acid sites is almost unchanged. The activity tests demonstrate that the catalytic activity of Pd-loaded ZSM-5/MCM-48 composite catalysts is much higher than that of Pd/ZSM-5 and Pd/MCM-48, and all these catalysts are active and stable in the total oxidation of benzene. Both $\mathrm{Pd}^{0}$ and $\mathrm{Pd}^{2+}$ are responsible for the oxidation reaction, and the catalytic activity is closely related to the support acidity, the $\mathrm{CO}_{2}$ desorption capability and the Pd dispersion. This research thus indicates that the novel composite materials have promised as active Pd-supported catalysts in the elimination of volatile organic compound (VOCs).
\end{abstract}

(C) 2010 Elsevier B.V. All rights reserved.

\section{Introduction}

Industrial waste gases contain large quantities of hazardous volatile organic compounds (VOCs), which are recognized as the major contributors to air pollution and are dangerous to human health and the environment [1]. Benzene is a notorious VOC present in various industries, such as chemical, petrochemical, paint and coating, and steel manufacturers. As a consequence, stringent environmental regulations have been developed and implemented in order to reduce the VOCs emission [2]. VOCs catalytic oxidation technology has been widely studied, due to the distinguished advantages, such as low thermal $\mathrm{NO}_{x}$ emission, high destructive efficiency, low operation and energy cost, and a relatively high flexibility $[3,4]$. At the same time, the proper selection and development of the catalyst is essential for successful removal of VOCs. Currently, different types of catalysts such as supported noble metals, metal oxides, and mixtures of noble metals and metal oxides are extensively investigated in VOCs catalytic oxidation [5,6]. Particularly, Pd-supported catalysts are extensively examined as Pd catalyst is promising for practical applications in hydrocarbons total combustion due to its high activity at relatively low temperatures and the high tolerance to the moisture [7-9].

\footnotetext{
* Corresponding author. Tel.: +86 10 62849194; fax: +861062923564.

** Corresponding author. Tel.: +61 7 33463809; fax: +61 733463973.

E-mail addresses: zpinghao@rcees.ac.cn(Z.Hao),gordonxu@uq.edu.au(Z.-P.Xu).
}

On the other hand, supports are an important component for the Pd-loaded catalysts as they often profoundly affect the generation of active species and the catalytic performance [10,12]. Niwa and co-workers [12] proposed that the activity of Pd-supported catalysts was very much dependent on the acid-base character of supports. They further demonstrated that the Brønsted acid sites were responsible for the formation of the dispersed Pd species, and the acid-base property of support had significant influence on the dispersion and oxidation state of Pd $[10,13,14]$. Different types of supports such as porous materials, alumina and silica are comprehensively investigated in hydrocarbons catalytic oxidation [15-18]. Among them, porous materials such as ZSM-5, MCM-41 and MCM-48 possess narrow pore size distribution, high surface area $\left(300-1100 \mathrm{~m}^{2} / \mathrm{g}\right)$, and potential ability to inhibit active particles growth and aggregation in their pores [19], appear to be one of the best supports for Pd-loaded catalysts.

Crystalline microporous zeolites have extensive applications in catalysis due to their high ion-exchange capacity, intrinsic acidity, high hydrothermal stability and shape selectivity. Especially, ZSM-5 zeolite possesses high resistance to deactivation, i.e., coke deposition [20]. Unfortunately, under the restriction of small pore sizes $(<1.5 \mathrm{~nm})$, such materials might be not suitable as catalysts for processing large molecules [21], such as benzene (molecular diameter: $0.66 \mathrm{~nm}$ ). Over the last decade, silica-based mesoporous materials such as M41S [22] have raised increasing interests due to their potential application as catalysts, adsorbents and molecular/supramolecular hosts especially for large molecular species 
$[21,23]$. However, these materials generally exhibit low hydrothermal stability and weak acidity due to their amorphous frameworks [24]. Thus, new synthesis strategies have been developed to obtain materials which combine the advantages of mesoporous materials and zeolites [25-34]. For instance, Pinnavaia and co-workers $[26,27]$ reported the assembly of steam stable aluminosilicate mesostructures using zeolite seeds such as ZSM-5, Y and Beta as building units or precursors. Beta/MCM- 41 composite materials containing an interconnected micropore and mesopore structure were successfully prepared by Guo et al. [28]. Recently, Kaliaguine and co-workers $[32,33]$ reported new approaches to prepare ultrastable and highly acidic micro/mesoporous materials by coating mesoporous materials with zeolite gel. It is well known that MCM48 has a special cubic three-dimensional structure that allows the smooth diffusion of reactants within the pores, subsequently leading to a better catalytic performance. However, most of the published reports on composite materials have focused on onedimensional MCM-41 as the mesostructured component [25-27], and little work has been done on the cubic mesoporous materials (such as MCM-48). Prokešová et al. [35] reported the preparation of Beta/MCM-48 composite materials via simultaneous hydrothermal treatment. However, the simultaneous hydrothermal process is very complicated and needs a long synthesis period. More recently, Xia and Mokaya [36] reported that the zeolite/MCM-48 composite materials can be synthesized via a simple recrystallization process, and the acidity and hydrothermal stability of the composite materials can be well controlled.

To the best of our knowledge, there is no report about the synthesis of ZSM-5/MCM-48 biporous materials with different acidities by controlling the amount of aluminum source published up to now. Simultaneously, we demonstrate that such a micro/mesoporous composite material can be effectively applied in VOCs catalytic oxidation. Moreover, the biporous materials probably have other potential application in adsorption and separation. The objectives of this research are: (1) to investigate a simple and reproducible procedure for the preparation of a new type of Pdloaded composite materials and its application in benzene catalytic oxidation; (2) to examine whether and how the support acidity affects the state and dispersion of Pd; and (3) to correlate the textural properties, the $\mathrm{Pd}$ state and dispersion, and the $\mathrm{CO}_{2}$ desorption capability with the catalytic activity of the Pd-supported composite materials for benzene oxidation. The experimental results suggest that the composite materials have been successfully synthesized, and their acidity is much stronger than that of the pure MCM- 48 . The number of strong acid sites increases with the Si/Al molar ratio falling, which seems to result in a better Pd dispersion. Moreover, all the prepared Pd-based ZSM-5/MCM-48 composite materials are stable and active catalysts for benzene oxidation, and their catalytic activity can be explained in terms of the specific surface area, the support acidity, the Pd dispersion and the $\mathrm{CO}_{2}$ desorption capability.

\section{Experimental}

\subsection{Catalyst synthesis}

The mciro/mesoporous composite materials were hydrothermally synthesized by assembling cetyltrimethylammonium bromide (CTAB) in a preformed ZSM-5 colloidal gel. Typically, the precursor zeolite colloidal suspension with the ZSM-5 primary unit was prepared by mixing $21.1 \mathrm{~g}$ of $\mathrm{H}_{2} \mathrm{O}, 7.1 \mathrm{~g}$ of $20 \mathrm{wt}$.\% tetrapropylammonium hydroxide (TPAOH), $10.6 \mathrm{~g}$ of tetraethyl orthosilicate (TEOS), and different amounts of aluminium isopropoxide under stirring for $2 \mathrm{~h}$. Then the mixture was aged at $100^{\circ} \mathrm{C}$ for $4 \mathrm{~h}$. After cooling to room temperature, the resulting ZSM-5 zeolite suspension was added with a CTAB solution containing a stoichiometrical amount of $\mathrm{NaOH}$ to a final gel molar composition of TEOS:OH:Al:CTAB: $\mathrm{H}_{2} \mathrm{O}=1: 0.5: x: 0.12: 118$. The prepared gel was continuously stirred for $2 \mathrm{~h}$ at room temperature, and then transferred into an autoclave and heated at $150{ }^{\circ} \mathrm{C}$ for $8 \mathrm{~h}$. The resulting solid material was obtained by filtration, dried at $60^{\circ} \mathrm{C}$ and calcined at $550{ }^{\circ} \mathrm{C}$ for $6 \mathrm{~h}$. Afterwards, the calcined sample was subjected to exchange with a $0.1 \mathrm{M} \mathrm{NH}_{4} \mathrm{NO}_{3}$ solution (two exchange cycles) for $24 \mathrm{~h}$ at room temperature and followed by calcination at $500^{\circ} \mathrm{C}$ for $4 \mathrm{~h}$ to obtain the protonated form. In this research, four samples with different Si/Al molar ratios $(x)$, denoted as ZM- $x(x=20,40,80$ and 160), were prepared.

For comparison, pure MCM-48 was synthesized following the literature procedure [37], i.e., $3.73 \mathrm{~g}$ of $\mathrm{CTAB}, 25 \mathrm{ml}$ of $\mathrm{H}_{2} \mathrm{O}, 0.48 \mathrm{~g}$ of $\mathrm{NaOH}$ and $5.26 \mathrm{~g}$ of TEOS were mixed under vigorously stirring for $30 \mathrm{~min}$, and followed by aging, filtration and calcination. ZSM5 zeolite $(\mathrm{Si} / \mathrm{Al}=25)$ was bought from Tianjin Chemical Plant and subject to the similar calcination.

The Pd-loaded catalyst with a nominal Pd loading of $0.3 \mathrm{wt} . \%$ was prepared by impregnating the porous support with a $\mathrm{PdCl}_{2}$ aqueous solution and drying at $100^{\circ} \mathrm{C}$ overnight, followed by calcination at $500^{\circ} \mathrm{C}$ for $4 \mathrm{~h}$ and reduction in a pure $\mathrm{H}_{2}$ stream $(30 \mathrm{ml} / \mathrm{min})$ at $480^{\circ} \mathrm{C}$ for $2 \mathrm{~h}$.

\subsection{Catalyst characterization}

X-ray diffraction (XRD) patterns were recorded on a Rigaku TTR2 powder diffraction system using $\mathrm{Cu} K \alpha$ radiation $(\lambda=0.15418 \mathrm{~nm})$ in the $2 \theta$ range of $0.7-4^{\circ}$ (scanning rate of $0.5^{\circ} / \mathrm{min}$ ) and $5-50^{\circ}$ (scanning rate of $4 \% \mathrm{~min}$ ), respectively. The exact Pd wt.\% in all calcined samples was determined by inductively coupled plasma optical emission spectroscopy (ICP-OES) on an OPTIMA 2000. The palladium dispersion was assessed by $\mathrm{H}_{2}$ chemisorption at $25^{\circ} \mathrm{C}$, i.e., the molar ratio of $\mathrm{H} / \mathrm{Pd}$ [38]. The mean Pd crystallite size was further estimated from the equation: $d(\mathrm{~nm})=112 /$ (percentage of Pd exposed) [39], assuming that the Pd crystallites were spherical with a surface atom density of $1.27 \times 10^{9}$ atoms $/ \mathrm{m}^{2} . \mathrm{N}_{2}$ adsorption/desorption isotherms of catalysts at $77 \mathrm{~K}$ were collected on a gas sorption analyzer NOVA1200. All samples were degassed under vacuum at $300^{\circ} \mathrm{C}$ for $3 \mathrm{~h}$ before the measurement. The total pore volume was estimated from the amount of nitrogen adsorbed at a relative pressure $\left(P / P_{0}\right)$ of $c a$. 0.99 . The specific surface area $\left(S_{\mathrm{BET}}\right)$ was calculated using the Brunauer-Emmett-Teller (BET) method (the micropore surface area and micropore volume were estimated by the $t$-plot method) and the pore size distribution (PSD) was derived from the desorption branch of the $\mathrm{N}_{2}$ isotherm using the Barrett-Joyner-Halenda (BJH) method. Thermogravimetric analysis (TGA) was performed on a Setaram Labsys, where ca. $15 \mathrm{mg}$ of finely ground sample was heated from 30 to $800^{\circ} \mathrm{C}$ at a heating rate of $10^{\circ} \mathrm{C} / \mathrm{min}$ with air flowing at $30 \mathrm{ml} / \mathrm{min}$. Infrared spectra were recorded using a Nicolet Nexus670 IR spectrometer by measuring the absorbance of the $\mathrm{KBr}$ pellet ( $2 \%$ sample and $98 \% \mathrm{KBr}$ ). Scanning electron microscopy (SEM) images were recorded on a Hitachi S-3000N microscope equipped with EDX detector for composition analysis of the as-synthesized catalysts. High-resolution transmission electron microscope (HRTEM) images were recorded on a FEI Tecnai G2 F20 U-TWIN microscope operating at an accelerating voltage of $200 \mathrm{kV}$. All samples were ground, dispersed in ethanol and deposited on the micro-grids prior to observation. Solid-state ${ }^{27} \mathrm{Al}$ MAS NMR spectra were performed on a Bruker AC$80 \mathrm{MHZ}$ spectrometer equipped with a $5 \mathrm{~mm}$ BBI detector, and a spinning frequency of $8 \mathrm{kHz}$, and the chemical shifts were referred to $\mathrm{Al}\left(\mathrm{H}_{2} \mathrm{O}\right)_{6}{ }^{3+}$. Temperature programmed desorption of $\mathrm{NH}_{3}$ and $\mathrm{CO}_{2}\left(\mathrm{NH}_{3}\right.$-TPD and $\mathrm{CO}_{2}$-TPD) were preformed on a Micromeritics chemisorb 2720 equipped with a TCD. Typically, $0.05 \mathrm{~g}$ of the catalyst was pre-treated in a pure helium flow $(50 \mathrm{ml} / \mathrm{min})$ at $300^{\circ} \mathrm{C}$ for 
$1 \mathrm{~h}$ and then cooled to room temperature $\left(25^{\circ} \mathrm{C}\right)$ prior to adsorption of $\mathrm{NH}_{3}\left(\mathrm{NH}_{3} / \mathrm{He}, 2 \% / 98 \%\right.$ in $\left.\mathrm{v} / \mathrm{v}\right)$ or $\mathrm{CO}_{2}\left(\mathrm{CO}_{2} / \mathrm{He}, 5 \% / 95 \%\right.$ in $\left.\mathrm{v} / \mathrm{v}\right)$ for $2 \mathrm{~h}$. After being saturated with $\mathrm{NH}_{3}$ or $\mathrm{CO}_{2}$, the catalyst was flushed with pure helium flow $(50 \mathrm{ml} / \mathrm{min})$ for $1 \mathrm{~h}$ at room temperature $\left(25^{\circ} \mathrm{C}\right)$ to remove the weakly physisorbed $\mathrm{NH}_{3}$ or $\mathrm{CO}_{2}$. The desorption profile of $\mathrm{NH}_{3}$-TPD and $\mathrm{CO}_{2}$-TPD were recorded from 25 to $850^{\circ} \mathrm{C}$ and $500^{\circ} \mathrm{C}$ at a heating rate of $10^{\circ} \mathrm{C} / \mathrm{min}$, respectively. $\mathrm{X}$-ray photoelectron spectroscopy (XPS) experiments were carried out on a Thermo Electron Escalab250 instrument using $\mathrm{Al} \mathrm{K \alpha}$ as the exciting radiation at constant pass energy of $50 \mathrm{eV}$. The $\mathrm{C} 1 \mathrm{~s}$ peak $(285.0 \mathrm{eV})$ was used to calibrate the binding energy (BE).

\subsection{Catalytic oxidation activities}

All evaluation experiments were performed in a continuousflow fixed-bed reactor at the atmospheric pressure, consisting of a stainless steel tube ( $6 \mathrm{~mm}$ i.d.) that was filled with the catalyst. The VOC-containing gas was generated by bubbling air through the VOC saturator, and then further diluted with another air stream before reaching the reaction bed. The temperatures of the catalyst bed and tubular electric furnace were monitored automatically by E-type thermocouples. In each test, $300 \mathrm{mg}$ of the catalyst (40-60 mesh) was placed at the middle of the tube reactor and the total flow rate was kept at $350 \mathrm{ml} / \mathrm{min}$, i.e., gas hourly space velocity (GHSV) of $32,000 \mathrm{~h}^{-1}$, and the $\mathrm{O}_{2}$ feed concentration was kept at about $21 \%$ $(\mathrm{v} / \mathrm{v})$. In each test, the catalyst bed temperature was first raised to $130{ }^{\circ} \mathrm{C}$ with the feed stream passing and stabilized for $30 \mathrm{~min}$. Then the temperature was increased to the next one at a heating rate of $5^{\circ} \mathrm{C} / \mathrm{min}$ and stabilized for $20 \mathrm{~min}$ prior to online analysis of the effluent gas composition in an Agilent gas chromatograph equipped with an FID and a TCD. VOC concentrations in the feed and effluent streams were determined with the FID after being separated in an $\mathrm{AB}-\mathrm{GASPRO}$ capillary column, and $\mathrm{CO} / \mathrm{CO}_{2}$ in the effluent stream were separated in a TDX-01 column and their concentrations were determined with the TCD.

\section{Results}

\subsection{Structural features of the composite materials}

Fig. 1 shows the XRD patterns in the $2 \theta$ range of $0.7-4^{\circ}$ and $5-50^{\circ}$ for Pd-based composite samples with various $\mathrm{Si} / \mathrm{Al}$ molar ratios. The XRD patterns of Pd/ZM-20, Pd/ZM-40 and Pd/ZM-80 are typical of the MCM-48 mesophase, belonging to the Ia3d space group $[21,23,35]$, with the (211) and (2 20$)$ diffraction peaks appearing at $2 \theta=2.5^{\circ}$ and $3.2^{\circ}$, respectively. Simultaneously, the zeolite phase is featured with many sharp peaks in the range of $10-40^{\circ}$. It is further noted that the intensity of the (211) peak attributed to MCM-48 decreases while the intensity of zeolite-featured peaks increases with the increase of the Si/Al molar ratio. These results indicate that a structurally ordered cubic MCM-48 was successfully assembled onto ZSM-5 zeolite seeds [40], to form biporous (micro- and mesoporous) materials hybridized with a cubic MCM-48 phase and ZSM-5 zeolite. The XRD pattern of Pd/ZM-20 indicates that there was just a MCM-48 phase as there were no characteristic zeolite peaks but only a board diffraction peak at $2 \theta \approx 25^{\circ}$, attributed to the non-crystalline silica within the walls of the mesophase [41].

In order to further investigate the presence of zeolite characteristics, TGA and IR spectroscopy were performed. Fig. 2 shows the TG and DTG curves of as-synthesized biporous composites. The DTG curves of ZM-40, ZM-80 and ZM-160 can be divided into four events (Fig. 2B). The first mass loss for all composite samples below $110^{\circ} \mathrm{C}$ (centered at $71^{\circ} \mathrm{C}$ ) is an endothermic process, due to the loss of molecular and adsorbed water [42]. The other three events are attributed to the different stages of decomposi-

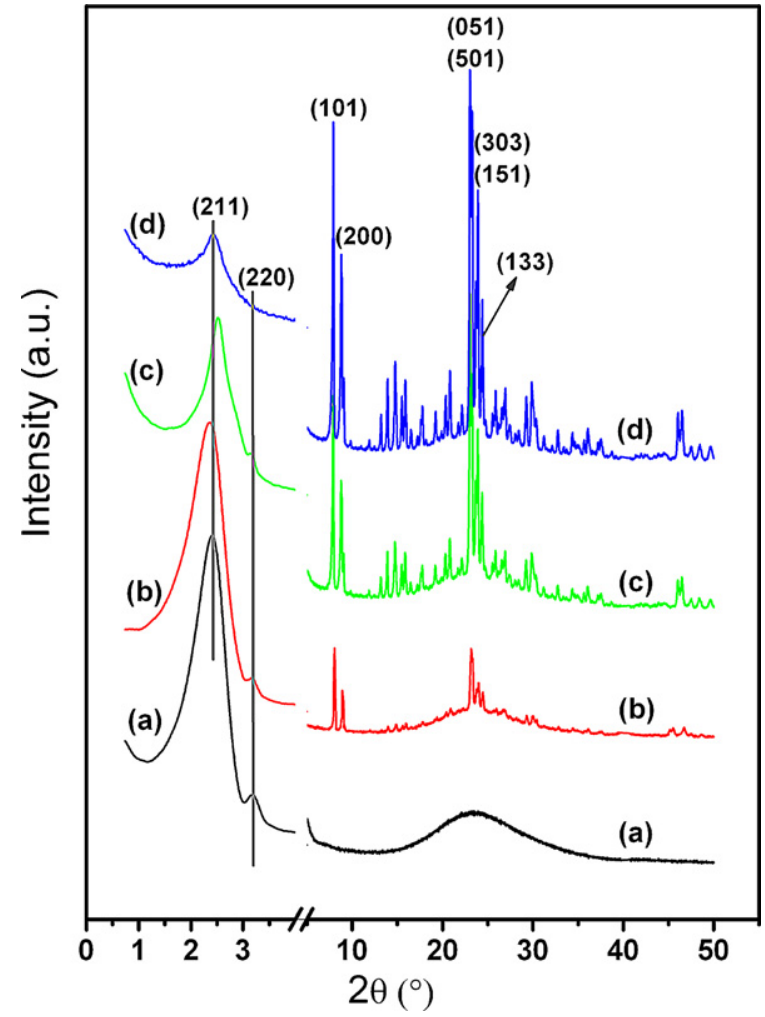

Fig. 1. X-ray diffraction patterns of the composite catalysts: (a) Pd/ZM-20, (b) Pd/ZM-40, (c) Pd/ZM-80 and (d) Pd/ZM-160.

tion of organic templates, such as CTAB and TPAOH. Noteworthily, the TG and DTG curves of these composites (except ZM-20) are different from those of pure MCM-48 (not shown) where decomposition of CTAB template only occurs between 150 and $300^{\circ} \mathrm{C}$ $[35,36]$. The mass loss between 150 and $300^{\circ} \mathrm{C}$ is also present for as-prepared mesophase materials (Fig. 2). However, there are two more mass losses between 320 and $560{ }^{\circ} \mathrm{C}$ for ZM-40, ZM-80 and ZM-160 (Fig. 2B), probably due to decomposition of TPAOH template used for the formation of zeolite seeds [35]. This analysis seemingly agrees with the XRD patterns (Fig. 1), suggesting that zeolite seeds are present in the mesostructure of MCM-48 materials. The FT-IR spectra of composite catalysts are shown in Fig. 3. The bands at ca. 451, 800, 1077 and $1110 \mathrm{~cm}^{-1}$ are due to the symmetric/asymmetric bending and stretching vibrations of $\mathrm{Si}-\mathrm{O}-\mathrm{Si}$ bonds $[36,43]$. Particularly, the band at $c a .560 \mathrm{~cm}^{-1}$ is attributed to the five- and six-membered rings of $\mathrm{T}-\mathrm{O}-\mathrm{T}(\mathrm{T}=\mathrm{Si}$ or $\mathrm{Al})$ in zeolite $[22,30-33]$, and gradually intensified with the increase of the $\mathrm{Si} / \mathrm{Al}$ molar ratio (Fig. 3), thus further evidencing the presence of zeolite subunits in ZM-40, ZM-80 and ZM-160.

The particle morphology and elemental composition of the synthesized biporous catalysts were investigated using SEM equipped with an EDX detector. Representative SEM images and elemental composition for various samples are shown in Fig. 4 and Table 1, respectively. $\mathrm{Pd} / \mathrm{ZM}-20$ particles are mostly irregular piece-like or solid shell-like with rough surface (Fig. 4A), similar to previous reports for MCM-48 [34,36,43]. The cubic/hexagonal particles with a typical diameter of $0.1-0.5 \mu \mathrm{m}$ appear in the other samples and the weight rises with the Si/Al molar ratio going up (Fig. 4B-D). The cubic particles can be attributed to the emergence of zeolitic ZSM5 phase [36]. Indeed, these morphological changes are consistent with increasing ZSM-5 content in composite samples (Figs. 1 and 3 ). With respect to the elemental composition, the $\mathrm{Si} / \mathrm{Al}$ ratio is lower than the expected value in all cases (Fig. 4 and Table 1), suggesting that some silicate is still in the solution while Al preferentially 
Table 1

Characteristic data and catalytic activity of synthesized catalysts.

\begin{tabular}{|c|c|c|c|c|c|c|c|}
\hline Sample & $\mathrm{Pd}^{\mathrm{a}}$ (wt.\%) & $\mathrm{Si} / \mathrm{Al}$ ratio ${ }^{\mathrm{b}}$ & $\mathrm{H} / \mathrm{Pd}^{\mathrm{c}}$ & $D_{\mathrm{c}}^{\mathrm{d}}(\mathrm{nm})$ & $T_{10}{ }^{\mathrm{e}}\left({ }^{\circ} \mathrm{C}\right)$ & $T_{50}{ }^{\mathrm{e}}\left({ }^{\circ} \mathrm{C}\right)$ & $T_{90}{ }^{\mathrm{e}}\left({ }^{\circ} \mathrm{C}\right)$ \\
\hline $\mathrm{Pd} / \mathrm{ZM}-20$ & 0.29 & 7.17 & 0.55 & 2.18 & 177 & 199 & 218 \\
\hline $\mathrm{Pd} / \mathrm{ZM}-40$ & 0.28 & 14.3 & 0.61 & 1.96 & 174 & 192 & 204 \\
\hline $\mathrm{Pd} / \mathrm{ZM}-80$ & 0.28 & 26.1 & 0.50 & 2.4 & 181 & 202 & 223 \\
\hline Pd/ZM-160 & 0.29 & 39.6 & 0.46 & 2.61 & 188 & 208 & 228 \\
\hline $\mathrm{Pd} / \mathrm{MCM}-48$ & 0.28 & 1 & 0.48 & 2.5 & 204 & 245 & 292 \\
\hline Pd/ZSM-5 & 0.27 & 25 & 0.39 & 3.07 & 186 & 224 & 244 \\
\hline
\end{tabular}

a Actual Pd contents obtained by the ICP-OES analysis.

b Actual Si/Al ratio estimated by the EDS analysis.

c Molar ratio of adsorbed hydrogen atoms to the total palladium atoms.

d Calculated diameters of the palladium crystallites based on the dispersion of Pd.

e Temperatures at which $10 \%, 50 \%$ and $90 \%$ conversion of benzene.

incorporates into the solid phase. On the other hand, the structure pore ordering and morphology of Pd/ZM-40 were further examined with high-resolution transmission electron microscopy (HRTEM, Fig. $4 \mathrm{E}-\mathrm{I}$ ). The images reveals that the MCM-48 phase possesses well-ordered pore structure with uniform pore size of $c a .3 .7 \mathrm{~nm}$, identical to the average pore size ( $c a .3 .5 \mathrm{~nm}$ ) derived from the $\mathrm{N}_{2}$ sorption (Table 2). Fig. $4 \mathrm{E}$ and $\mathrm{G}$ illuminates that the zeolite nanoparticles are tightly combined with the MCM-48 mesoporous phase.

Fig. 5 shows the ${ }^{27} \mathrm{Al}$ MAS NMR spectra of Pd/ZM-20 and Pd/ZM40. Both spectra show two resonances at around 54.8 and $0.1 \mathrm{ppm}$. The intense peak (54.8 ppm) is normally assigned to the chemical shift of tetrahedral coordinated aluminum [44] and the other peak $(0.1 \mathrm{ppm})$ with a lower intensity to the octahedral $\mathrm{Al}$, i.e., the extraframework Al species or the framework Al located at the defect sites $[44,45]$. The relative intensity indicates that most of $\mathrm{Al}$ atoms are tetrahedral coordinated and incorporated into the framework of the composite catalysts.

\subsection{Textural properties of the composite catalysts}

The $\mathrm{N}_{2}$ adsorption/desorption isotherms and the BJH pore size distribution calculated from the desorption branch for Pd/ZM- $x$ and Pd/MCM-48 (Supplementary materials, Fig. S1) show that all composite catalysts exhibit a typical irreversible type IV adsorption/desorption isotherms with well expressed H1-type hysteresis loops [46] at relative pressures $P / P_{0}$ of $0.2-0.4$ and $0.8-1.0$ (Fig. S1A). Correspondingly, the pore size distribution reveals that there are two types of pores in the composites centered at 2.4 and $3.8 \mathrm{~nm}$, respectively (Fig. S1B). The first condensation step on the isotherm at low relative pressure $\left(P / P_{0}=0.2-0.4\right)$ is characteristic of capillary condensation of framework-confined mesopores [23], and the sec- ond condensation step on the isotherm at $P / P_{0}=0.8-1.0$ indicates the presence of a significant amount of textural pores contributed to the filling of interparticle spaces [47]. It is noteworthy that Pd/ZM160 exhibits a high degree of mesoporous character although it possesses a high content of zeolitic material (Fig. S1A). For pure MCM-48, the so-called textural porosity is not observed as the hysteresis at $P / P_{0}=0.8-1.0$ is invisible. Moreover, the isotherms suggest that the pore size distribution of MCM-48 is relatively narrow (centered at $c a .2 .7 \mathrm{~nm}$ ) as the steep rise of the isotherm at $P / P_{0}=0.2-0.4$ (Fig. S1A). Table 2 lists the specific surface area $\left(S_{\mathrm{BET}}\right)$, mean pore diameter $\left(D_{\mathrm{p}}\right)$, total pore volume $\left(D_{\mathrm{V}}\right)$, micropore surface area $\left(S_{\mathrm{Mi}-\mathrm{BET}}\right)$ and micropore volume $\left(D_{\mathrm{Mi}-\mathrm{V}}\right)$ of fresh and used catalysts. The $S_{\mathrm{BET}}$ of the composite catalysts (between 952.6 and $\left.1003 \mathrm{~m}^{2} / \mathrm{g}\right)$ is a bit smaller than Pd/MCM-48 $\left(1029 \mathrm{~m}^{2} / \mathrm{g}\right)$ but much larger than Pd/ZSM-5 $\left(326.4 \mathrm{~m}^{2} / \mathrm{g}\right)$. In contrast, $D_{\mathrm{p}}$ of the composite catalysts $(\geq 3.2 \mathrm{~nm}$ ) is much larger than the mesoporous $\mathrm{Pd} / \mathrm{MCM}-48(2.4 \mathrm{~nm})$. In particular, Pd/ZM-40 has the largest $S_{\mathrm{BET}}$ $\left(1003 \mathrm{~m}^{2} / \mathrm{g}\right), D_{\mathrm{v}}\left(0.874 \mathrm{~cm}^{3} / \mathrm{g}\right)$ and $D_{\mathrm{p}}(3.5 \mathrm{~nm})$. On the other hand, the higher $\mathrm{Si} / \mathrm{Al}$ molar ratio is beneficial to the formation of microporous ZSM-5 as $S_{\mathrm{BET}}$ and $D_{\mathrm{v}}$ contributed to micropores (i.e., $S_{\mathrm{Mi} \text {-BET }}$ and $\left.D_{\mathrm{Mi}-\mathrm{V}}\right)$ increase with the increase of the Si/Al molar ratio (Table 2), which is well consistent with the observation from the XRD patterns (Fig. 1). As seen in Table 2, Pd/ZM-20 does not exhibit any microporosity, while the $S_{\mathrm{Mi}-\mathrm{BET}}$ and $D_{\mathrm{Mi}-\mathrm{V}}$ contribution are high up to $30.6 \%\left(S_{\text {Mi-BET }}=291.4 \mathrm{~m}^{2} / \mathrm{g}\right)$ and $29.7 \%\left(D_{\mathrm{Mi}-\mathrm{V}}=0.192 \mathrm{~cm}^{3} / \mathrm{g}\right)$ in $\mathrm{Pd} / \mathrm{ZM}-160$, respectively.

The $\mathrm{NH}_{3}$-TPD was performed to evaluate the acid strength and acid site number of the synthesized composite catalysts, as displayed in Fig. 6. The desorption temperature and quantitative mole number of acid sites are listed in Table 3. In general, all the composite catalysts exhibit three desorption peaks in the range of $110-770^{\circ} \mathrm{C}$, which means that there are three types of acid sites.

Table 2

Textural properties of the fresh and used catalysts.

\begin{tabular}{|c|c|c|c|c|c|}
\hline Sample & $S_{\mathrm{BET}^{\mathrm{a}}}\left(\mathrm{m}^{2} / \mathrm{g}\right)$ & $D_{\mathrm{V}^{\mathrm{b}}}^{\mathrm{b}}\left(\mathrm{cm}^{3} / \mathrm{g}\right)$ & $S_{\text {Mi-BET }}{ }^{c}\left(\mathrm{~m}^{2} / \mathrm{g}\right)$ & $D_{\mathrm{Mi}-\mathrm{V}}^{\mathrm{d}}\left(\mathrm{cm}^{3} / \mathrm{g}\right)$ & $D_{\mathrm{p}}^{\mathrm{e}}(\mathrm{nm})$ \\
\hline Pd/ZM-20 & 956.9 & 0.722 & I & 1 & 3.4 \\
\hline Pd/ZM-40 & 1003 & 0.874 & 87 & 0.056 & 3.5 \\
\hline Pd/ZM-80 & 967.9 & 0.786 & 252.9 & 0.143 & 3.2 \\
\hline Pd/ZM-160 & 952.6 & 0.645 & 291.4 & 0.192 & 3.2 \\
\hline Pd/MCM-48 & 1029 & 0.810 & 1 & 1 & 2.4 \\
\hline Pd/ZSM-5 & 326.4 & 0.208 & 297.9 & 0.150 & 1 \\
\hline Pd/ZM-20-used & 857 & 0.642 & 63.1 & 0.092 & 3.2 \\
\hline Pd/ZM-40-used & 918.4 & 0.726 & 114.8 & 0.076 & 3.3 \\
\hline Pd/ZM-80-used & 829.7 & 0.618 & 256.3 & 0.151 & 3.1 \\
\hline Pd/ZM-160-used & 775.8 & 0.456 & 177.2 & 0.122 & 3.3 \\
\hline Pd/MCM-48-used & 747.9 & 0.543 & 1 & 1 & 2.1 \\
\hline Pd/ZSM-5-used & 298.1 & 0.152 & 252.3 & 0.114 & 1 \\
\hline
\end{tabular}

a BET specific surface area.

b Total pore volume estimated at $P / P_{0}=0.99$.

c Micropore surface area.

d micropore volume estimated from the $t$-plot method.

e $\mathrm{BJH}$ pore diameter calculated from the desorption branch. 
Table 3

Acidity of as-synthesized aluminosilicate composite catalysts.

\begin{tabular}{|c|c|c|c|c|c|c|c|}
\hline \multirow[t]{2}{*}{ Sample } & \multicolumn{3}{|c|}{ Desorption peak temperature $\left({ }^{\circ} \mathrm{C}\right)$} & \multicolumn{4}{|c|}{ Acidity ${ }^{\mathrm{a}}$ (mmol $\mathrm{NH}_{3} /$ g cat.) } \\
\hline & I & II & III & I & II & III & $\mathrm{I}+\mathrm{II}+\mathrm{III}$ \\
\hline Pd/ZM-20 & 126 & 346 & 667 & 0.13 & 0.08 & 0.16 & 0.37 \\
\hline $\mathrm{Pd} / \mathrm{ZM}-40$ & 119 & 387 & 769 & 0.11 & 0.12 & 0.13 & 0.36 \\
\hline Pd/ZM-80 & 114 & 333 & 642 & 0.12 & 0.09 & 0.06 & 0.27 \\
\hline Pd/ZM-160 & 116 & 351 & 655 & 0.12 & 0.05 & 0.04 & 0.21 \\
\hline Pd/MCM-48 & 229 & 1 & l & 0.02 & 1 & 1 & 0.02 \\
\hline Pd/ZSM-5 & 245 & 408 & 742 & 0.15 & 0.23 & 0.03 & 0.41 \\
\hline
\end{tabular}

a Amounts of desorbed $\mathrm{NH}_{3}$ at different temperatures.

$\mathrm{Pd} / \mathrm{ZM}-40$ seems to have the strongest acidity as desorption occurs at the highest temperatures $\left(119,387\right.$ and $\left.769^{\circ} \mathrm{C}\right)$ in each event. The number of strong acid sites (desorption peak $>640^{\circ} \mathrm{C}$ in this work) in the composite catalysts increases with the $\mathrm{Si} / \mathrm{Al}$ ratio falling,
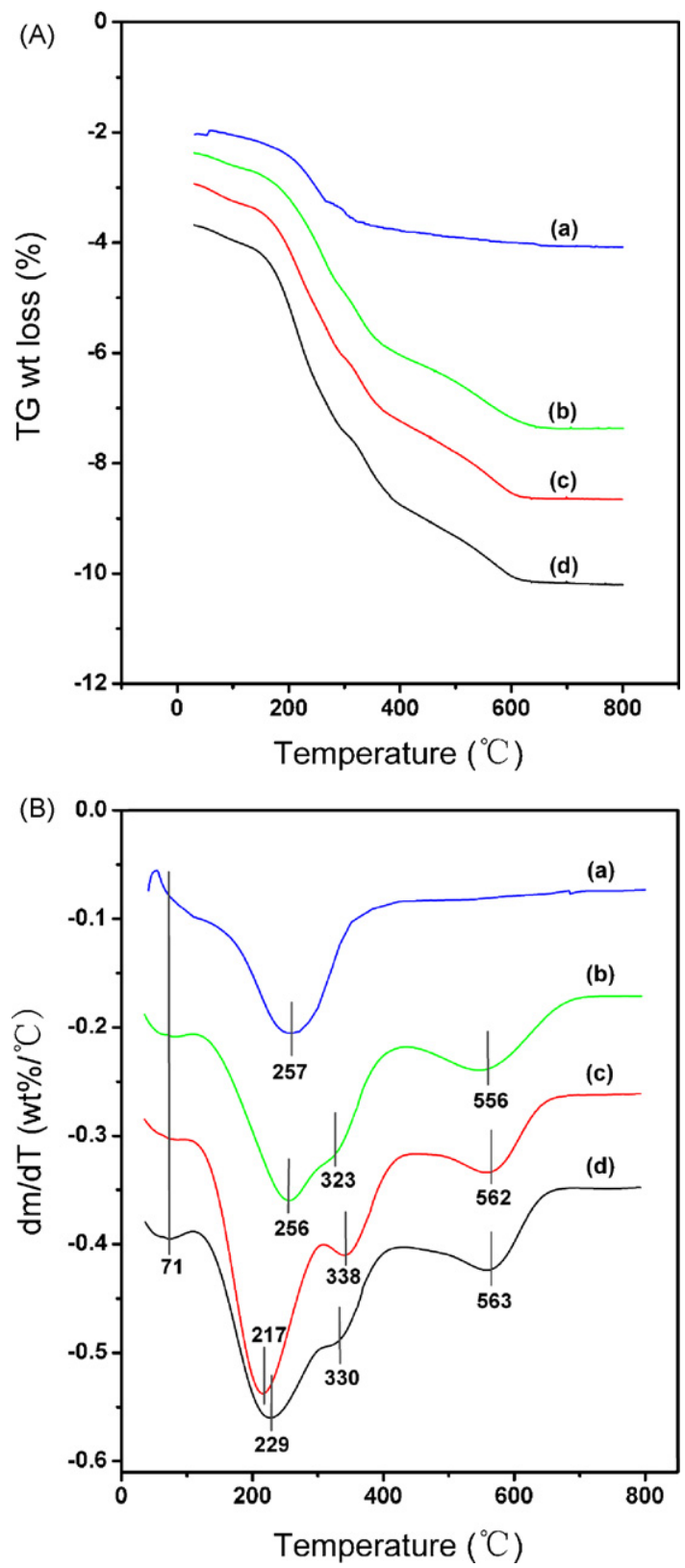

Fig. 2. TG (A) and DTG (B) curves of as-synthesized composite materials obtained from precursor ZSM-5 zeolite species aged at 150 for 8 h: (a) ZM-20, (b) ZM-40, (c) ZM-80 and (d) ZM-160. while the number of weak acid sites (desorption peak at about $120^{\circ} \mathrm{C}$ ) in the composites is almost unchanged. Overall, the total acid sites number of the composite catalysts increases with the decrease of the $\mathrm{Si} / \mathrm{Al}$ ratio (Table 3 ).

\subsection{Catalytic oxidation of benzene}

The light-off curves were used to compare the activity of the synthesized catalysts for benzene catalytic oxidation, as shown in Fig. 7. The products detected in the effluent are only $\mathrm{CO}_{2}$ and $\mathrm{H}_{2} \mathrm{O}$. In general, the composite catalysts (complete oxidation occurs in the vicinity of $240^{\circ} \mathrm{C}$ ) are more active than $\mathrm{Pd} / \mathrm{ZSM}-5$ (complete oxidation occurs at $270^{\circ} \mathrm{C}$ ) and Pd/MCM-48 (complete oxidation occurs at $315^{\circ} \mathrm{C}$ ). Table 1 presents the reaction temperatures of $T_{10}, T_{50}$ and $T_{90}$ for benzene conversion over these catalysts. $\mathrm{Pd} / \mathrm{ZM}-40$ possesses the highest activity with $90 \%$ benzene decomposed at $204^{\circ} \mathrm{C}$. The temperature reduction is more than $80^{\circ} \mathrm{C}$ when comparing with Pd/MCM-48 that causes a $90 \%$ benzene conversion at $292^{\circ} \mathrm{C}$. According to $T_{50}$ (Table 1 ), the activity order of prepared catalysts is as follows: Pd/ZM-40 $\left(192^{\circ} \mathrm{C}\right)>\mathrm{Pd} / \mathrm{ZM}-$ $20\left(199^{\circ} \mathrm{C}\right)>\mathrm{Pd} / \mathrm{ZM}-80\left(202^{\circ} \mathrm{C}\right)>\mathrm{Pd} / \mathrm{ZM}-160\left(208^{\circ} \mathrm{C}\right)>\mathrm{Pd} / \mathrm{ZSM}-5$ $\left(224^{\circ} \mathrm{C}\right)>\mathrm{Pd} / \mathrm{MCM}-48\left(245^{\circ} \mathrm{C}\right)$. On the other hand, in comparison with other Pd-loaded active catalysts reported elsewhere [48-51], our catalysts possess very good performance in deep catalytic

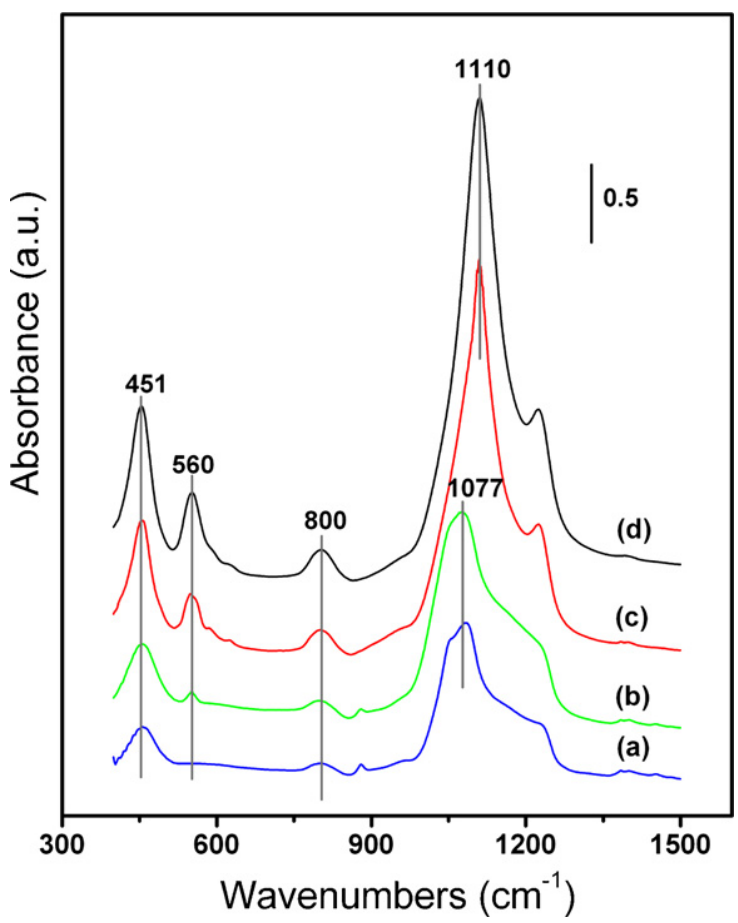

Fig. 3. FT-IR spectra of synthesized catalysts: (a) Pd/ZM-20, (b) Pd/ZM-40, (c) $\mathrm{Pd} / \mathrm{ZM}-80$ and (d) Pd/ZM-160. 

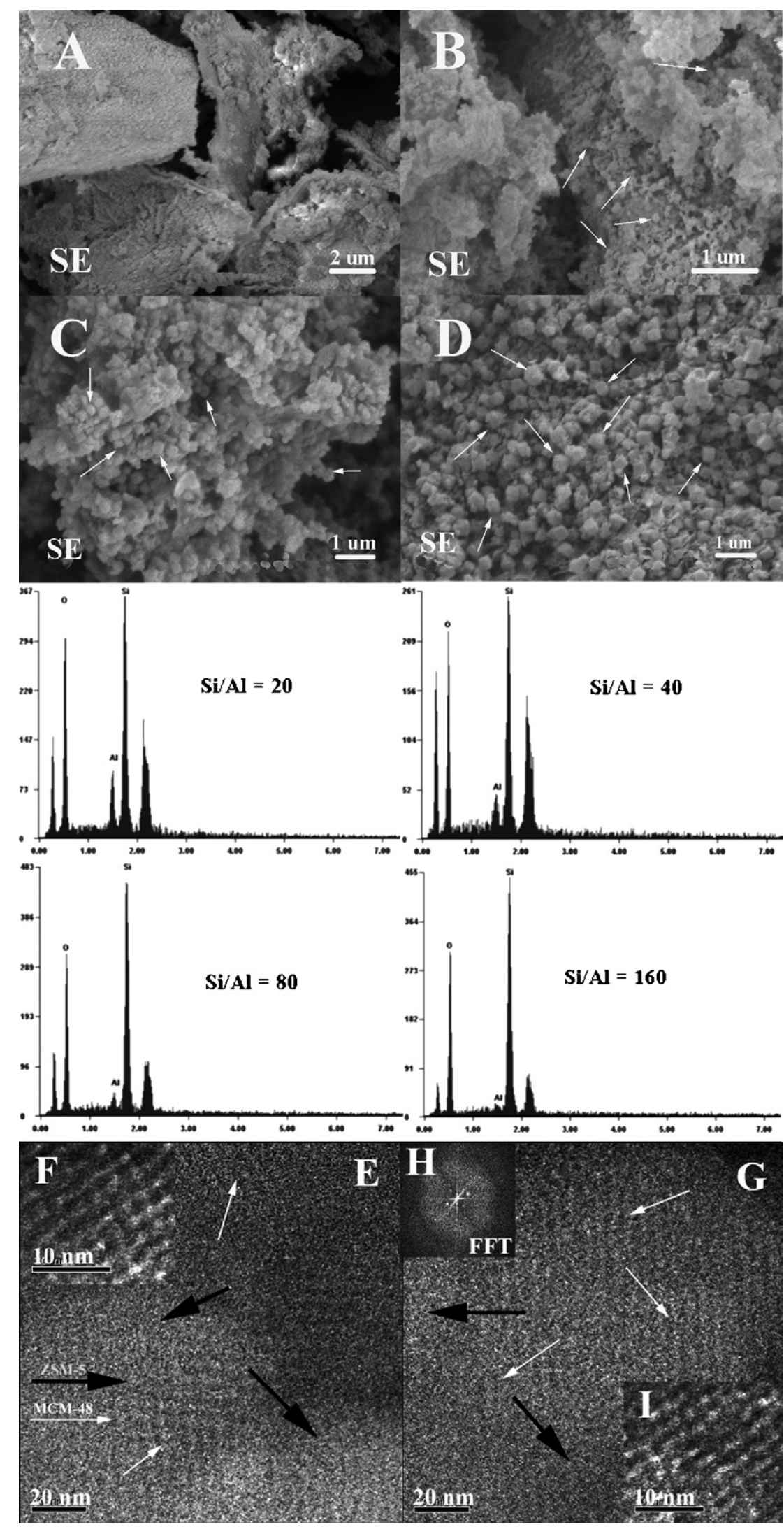

Fig. 4. Representative SEM, EDS, and HRTEM images of selected catalysts. SEM and EDS: (a) Pd/ZM-20, (b) Pd/ZM-40, (c) Pd/ZM-80, (d) Pd/ZM-160; HRTEM: (E-G) and (I) $\mathrm{Pd} / \mathrm{ZM}-40$. Insert is the selected-area FFT (H) pattern. 
Table 4

Summary of benzene oxidation catalysts that are known to perform better.

\begin{tabular}{|c|c|c|c|c|c|}
\hline \multirow[t]{2}{*}{ Sample } & \multicolumn{3}{|c|}{ Reaction conditions } & \multirow[t]{2}{*}{$T_{90}\left({ }^{\circ} \mathrm{C}\right)$} & \multirow[t]{2}{*}{ Reference } \\
\hline & Pd (wt.\%) & $\operatorname{GHSV}\left(h^{-1}\right)$ & $C_{\mathrm{Bz}}^{\mathrm{a}}(\mathrm{ppm})$ & & \\
\hline $\mathrm{Pd} / \mathrm{ZM}-40$ & 0.28 & 32,000 & 1500 & 209 & This work \\
\hline $\mathrm{Pd} / \mathrm{V}_{2} \mathrm{O}_{5} / \mathrm{Al}_{2} \mathrm{O}_{3}$ & 0.80 & 30,000 & 482 & 270 & {$[48]$} \\
\hline $\mathrm{Pd} / \mathrm{Ce} / \mathrm{Al}-\mathrm{PILC}{ }^{\mathrm{b}}$ & 0.20 & 20,000 & $<160$ & 250 & [49] \\
\hline $\mathrm{Pd}-\mathrm{Pt} / \gamma-\mathrm{Al}_{2} \mathrm{O}_{3}$ & 2.0 & 15,000 & 1000 & 225 & [50] \\
\hline $\mathrm{Pd} / \mathrm{SiO}_{2}$ & 1.55 & 800 & 2550 & 197 & [51] \\
\hline
\end{tabular}

a Benzene inlet concentration.

b Al-PILC: alumina pillared clays.

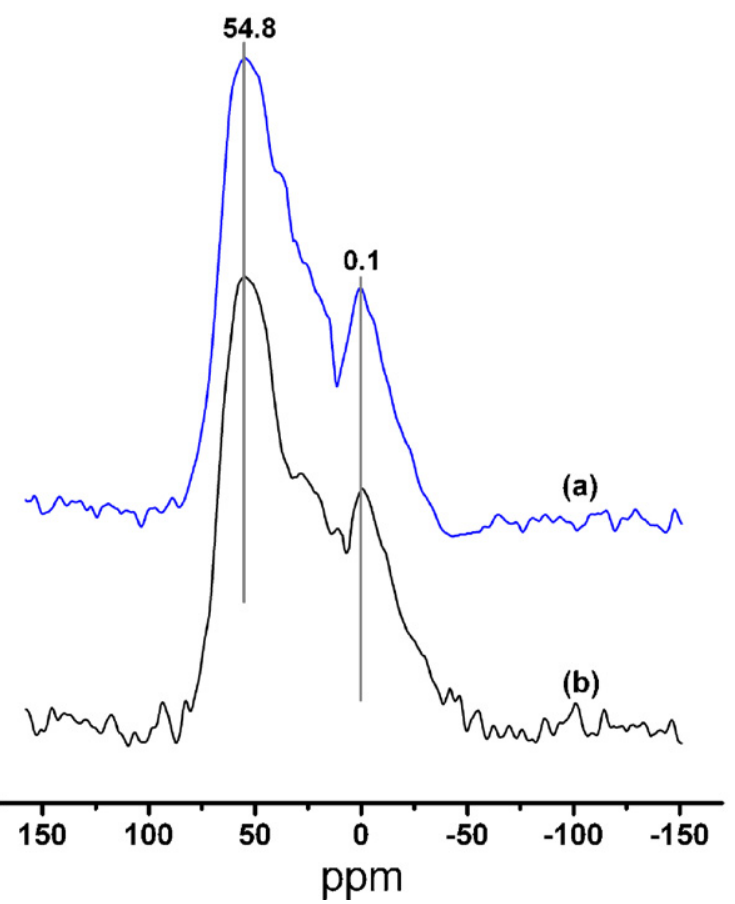

Fig. 5. Solid-state ${ }^{27} \mathrm{Al}$ MAS NMR spectra of (a) Pd/ZM-20 and (b) Pd/ZM-40.

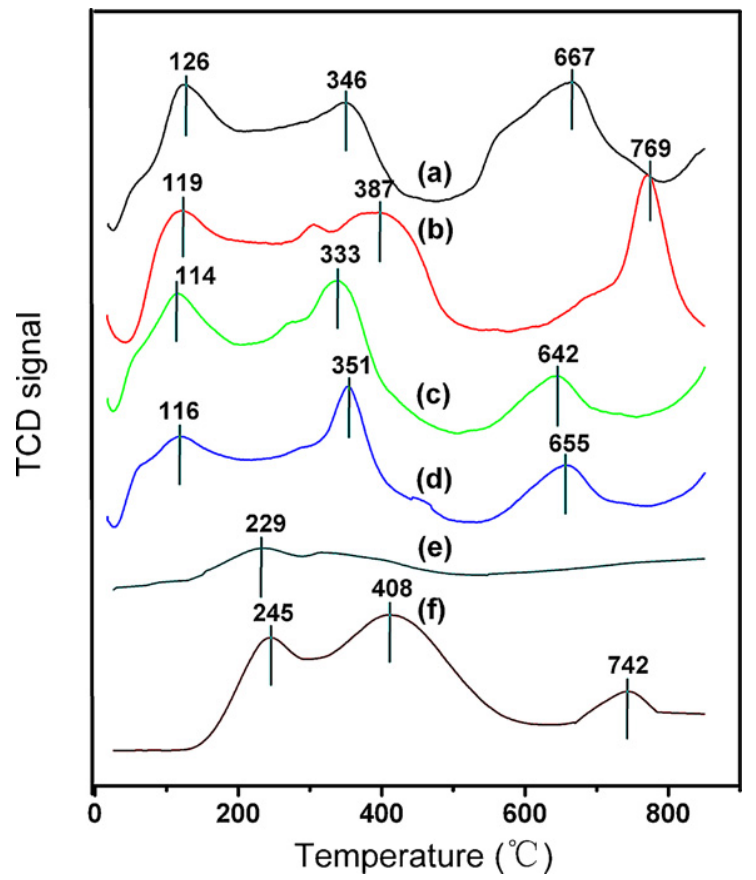

Fig. 6. $\mathrm{NH}_{3}$-TPD curves of composite catalysts: (a) Pd/ZM-20, (b) $\mathrm{Pd} / \mathrm{ZM}-40$, (c) Pd/ZM-80, (d) Pd/ZM-160, (e) Pd/MCM-48 and (f) Pd/ZSM-5.

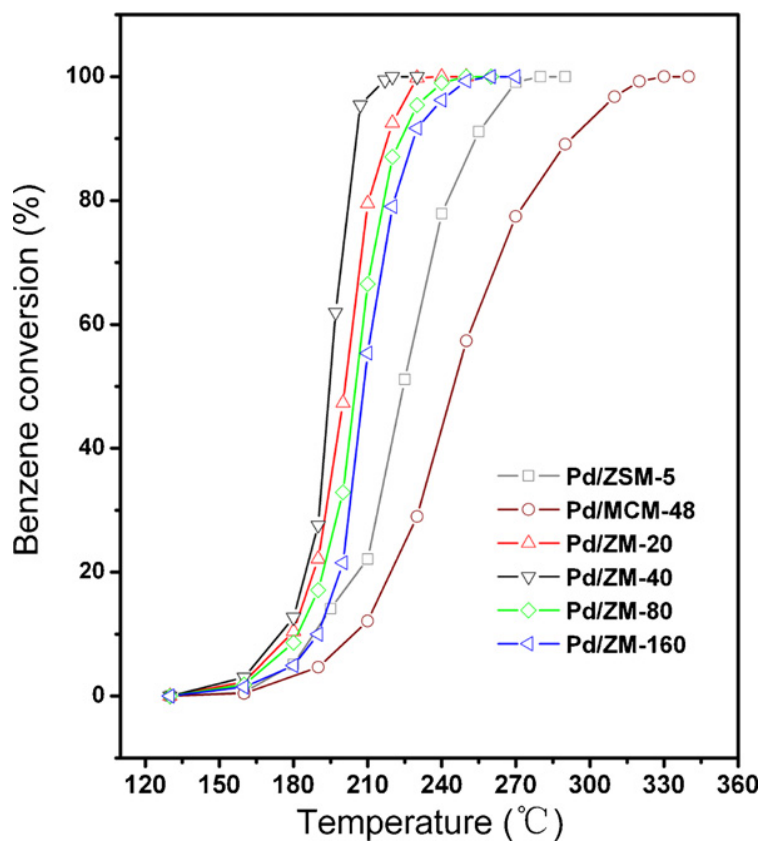

Fig. 7. Conversion profiles of benzene oxidation over various Pd-loaded catalysts.

oxidation of benzene, as shown in Table 4. Generally, the oxidation temperatures for $90 \%$ benzene conversion are higher than $220^{\circ} \mathrm{C}$ (Table 4). Noticeably, Lambert et al. [51] reported an interesting result for benzene oxidation over $\mathrm{Pd} / \mathrm{SiO}{ }_{2}$ xerogel catalyst $\left(T_{90}=197^{\circ} \mathrm{C}\right)$, as can be seen in Table 4 . However, the synthesis procedures for this catalyst are very complex and the GHSV (about $\left.800 \mathrm{~h}^{-1}\right)$ was much lower than our work $\left(32,000 \mathrm{~h}^{-1}\right)$. The above results suggested that the synthesized composite materials in our work are powerful and practical catalysts for benzene oxidation.

XPS spectra of fresh and used Pd/ZM-40 catalysts are shown in Fig. 8. The binding energies of Pd3d are found at around 335.1 and $341.4 \mathrm{eV}$ for the fresh catalyst, indicating the presence of $\mathrm{Pd}^{0}$, as reported elsewhere [52,53]. As for the used Pd/ZM-40 catalyst, the Pd3d binding energies are centered at 335, 337.1 and $341.5 \mathrm{eV}$, which can be attributed to $\mathrm{Pd}^{2+}(337.1 \mathrm{eV})$ [54] and $\mathrm{Pd}^{0}$ (335 and $341.5 \mathrm{eV}$ ), respectively. It is also noted that fresh Pd/ZM40 only contains $\mathrm{Pd}^{0}$ while the used one has predominant $\mathrm{Pd}^{2+}$ species.

\section{Discussion}

The ZSM-5/MCM-48 composite materials with various acidities and enhanced thermal stability have been successfully prepared by a simple crystallization approach. All Pd-impregnated materials are powerful catalysts in the elimination of benzene, and the superior catalytic activity of Pd/ZSM-5/MCM- 48 can be correlated to the improved $\mathrm{Pd}$ dispersion, $\mathrm{CO}_{2}$ desorption capability and acidity. 


\subsection{Pd dispersion on the synthesized catalysts}

In general, a larger surface area of the support is beneficial to the active phase dispersion. However, the Pd dispersion in this work is not only determined by the specific surface area (Tables 1 and 2). Okumura et al. and Muto et al. $[10,12,14]$ reported that the support acid property is one of the important factors that determine the Pd dispersion. In our previous work, we also found that Pd atoms are prone to disperse on the support with more acid sites (especially the strong acid sites) and a larger surface area [37]. Considering the catalyst acidity (Pd/ZSM-5 $>$ Pd/ZM-20 $\geq \mathrm{Pd} / \mathrm{ZM}-$ $40>\mathrm{Pd} / \mathrm{ZM}-80>\mathrm{Pd} / \mathrm{ZM}-160>\mathrm{MCM}-48$ ), we expect that both the specific surface area and the acidity promote the Pd dispersion (Table 1).

\subsection{Catalysts textural properties, $\mathrm{CO}_{2}$ desorption and benzene oxidation activity}

It is well known that there are many factors, such as the support nature (acidity and textural properties) $[5,10,14,52]$ and the active phase state (valence state and dispersion) $[9,55,56]$, affecting the catalytic activity. On the other hand, $\mathrm{CO}_{2}$ desorption capability may also be correlated to the catalytic activity although this property is seldom considered. In this work, $\mathrm{CO}_{2}$-TPD was performed over the fresh composite catalysts, as shown in Fig. 9. Obviously, $\mathrm{CO}_{2}$ is easiest desorption from Pd/ZM-40 surface as the primary desorption peak is located at the lowest temperature $\left(86^{\circ} \mathrm{C}\right)$. Next to $\mathrm{Pd} / \mathrm{ZM}$ $40, \mathrm{Pd} / \mathrm{ZM}-20$ also possesses a good $\mathrm{CO}_{2}$ desorption performance with the main desorption peaks centered at 89 and $283^{\circ} \mathrm{C}$, respectively. As indicated in Fig. 9, the $\mathrm{CO}_{2}$ desorption capability obeys the following order: Pd/ZM-40 $>$ Pd/ZM-20 $>$ Pd/ZM-80 $>$ Pd/ZM$160>\mathrm{Pd} / \mathrm{ZSM}-5>\mathrm{Pd} / \mathrm{MCM}-48$, which is consistent with the activity sequence for benzene catalytic oxidation (Fig. 7).

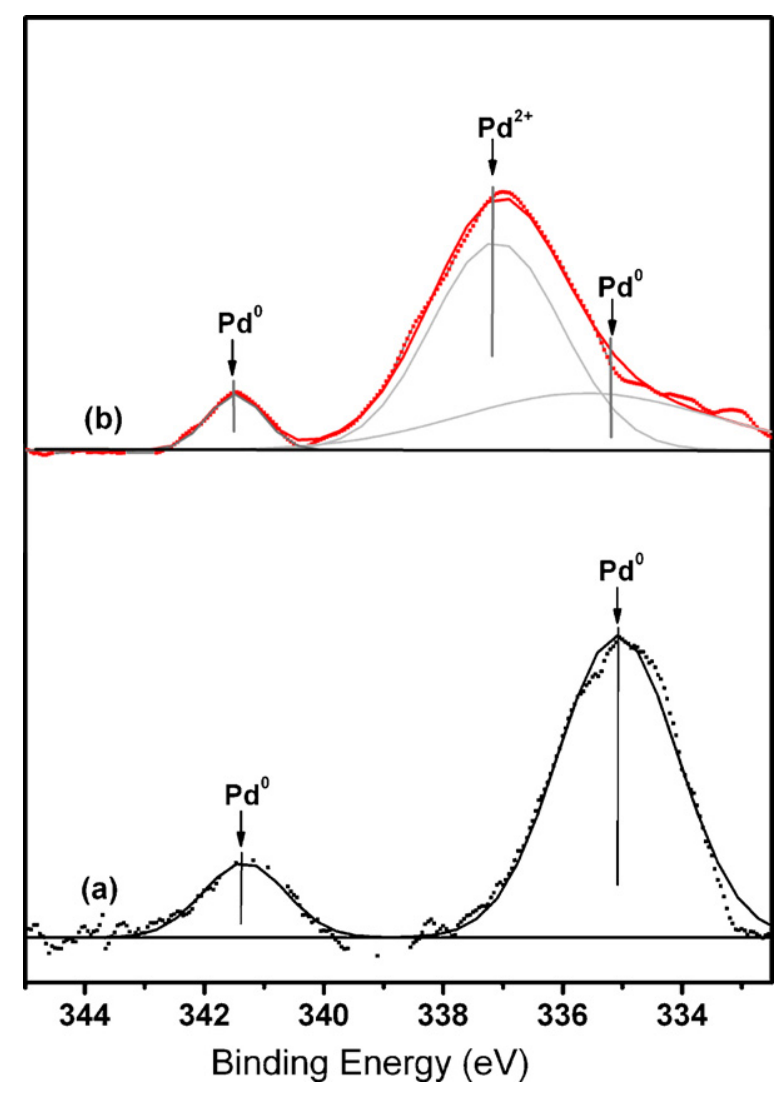

Fig. 8. XPS spectra of (a) Pd/ZM-40, (b) Pd/ZM-40-used.

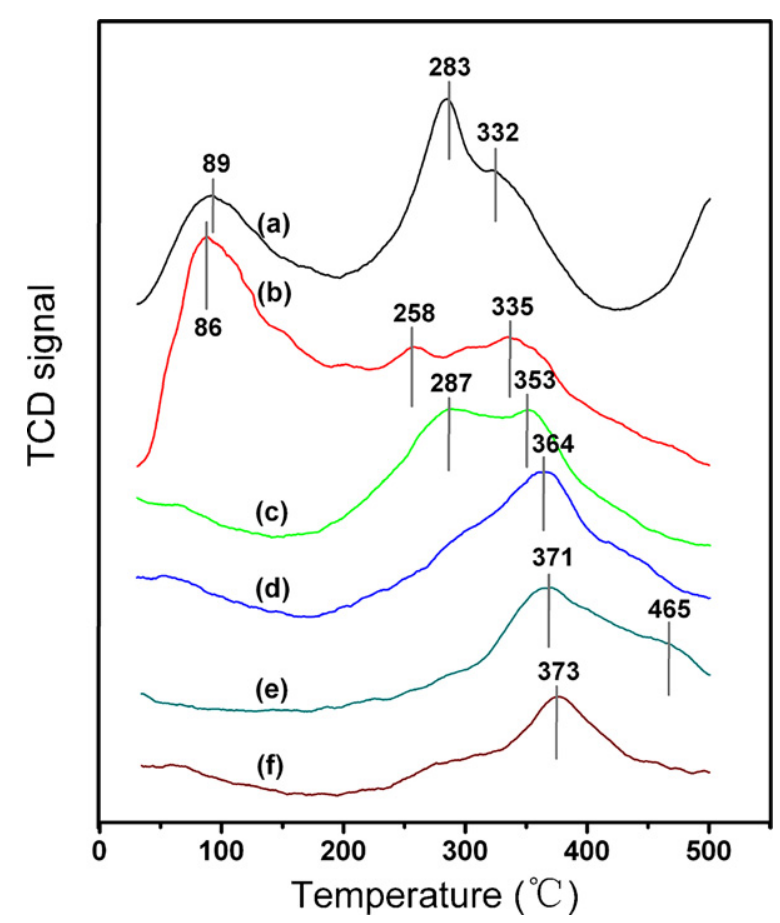

Fig. 9. $\mathrm{CO}_{2}$-TPD patterns of synthesized catalysts: (a) Pd/ZM-20, (b) Pd/ZM-40, (c) Pd/ZM-80, (d) Pd/ZM-160, (e) Pd/MCM-48 and (f) Pd/ZSM-5.

Moreover, there are different reports in the literature regarding the effect of the Pd state on hydrocarbons catalytic oxidation [54]. As for the active phase in VOCs oxidation over Pd-supported catalysts, i.e., $\mathrm{Pd}^{0}, \mathrm{Pd}^{2+}$ or a mixed $\mathrm{Pd}^{0} / \mathrm{Pd}^{2+}$ phase, some investigators propose that the most active phase is the mixture of $\mathrm{Pd}^{0}$ and $\mathrm{Pd}^{2+}$, as $\mathrm{Pd}^{2+}$ is active in hydrocarbons combustion, and the presence of $\mathrm{Pd}^{0}$ can also enhance the catalytic activity by providing more active sites for VOCs dissociation $[5,10,39,54,55]$, while others claim that $\mathrm{Pd}^{0}$ is the most active phase in VOCs catalytic oxidation and its stability is a vital factor for a catalyst [6]. The XPS result shows that the fresh catalyst in this work only contains $\mathrm{Pd}^{0}$ while the used one has predominant $\mathrm{Pd}^{2+}$ species, thus, we could expect that both $\mathrm{Pd}^{0}$ and $\mathrm{Pd}^{2+}$ are responsible for the oxidation reactions. It is generally accepted that the Mars-van Krevelen model is usually valid for hydrocarbons oxidation over Pd-supported catalysts [57]. This model assumes the reaction occurs when reactant molecules interact with oxygen-rich sites, and then $\mathrm{Pd}$ is alternately reduced $\left(\mathrm{Pd}^{0}\right)$ and oxidized $\left(\mathrm{PdO}_{x}\right)$. Fig. S3 in the supplementary materials shows the $\mathrm{H}_{2}$-TPR of the composite catalysts. Only a negative peak (around $70{ }^{\circ} \mathrm{C}$ ) can be observed for all samples due to the desorption of weakly adsorbed hydrogen and the decomposition of $\mathrm{PdH}_{x}[58,59]$, indicating that $\mathrm{PdCl}_{2}$ or $\mathrm{PdO}$ gets reduced easily to metal $\mathrm{Pd}$ in $\mathrm{H}_{2}$ atmosphere at ambient temperature [52], which is also expectedly happening in the hydrocarbon atmosphere. This result is in well agreement with the XPS measurement (Fig. 8). When $\mathrm{O}_{2}$ is present in the reactant feed mixture, a portion of $\mathrm{Pd}^{0}$ gets oxidized to active $\left[\mathrm{Pd}^{2+} \mathrm{O}^{2-}\right]$ species [11]. Firstly, the oxidized catalyst $\left(\left[\mathrm{Pd}^{2+} \mathrm{O}^{2-}\right]\right)$ is reduced by benzene and at the same time the benzene is oxidized to $\mathrm{CO}_{2}$ and $\mathrm{H}_{2} \mathrm{O}$. And then the catalyst redox center $\left(\mathrm{Pd}^{0}\right)$ is oxidized by the stream $\mathrm{O}_{2}$ to recover $\mathrm{Pd}^{2+} \mathrm{O}^{2-}$ through adsorption and dissociation of $\mathrm{O}_{2}$. As a consequence, the $\mathrm{CO}_{2}$ desorption capability in the first step probably plays an important role in the whole catalytic reaction. Indeed, benzene catalytic activity order follows the sequence of $\mathrm{CO}_{2}$ desorption order in this work (Figs. 7 and 9). In this work, it is worth noting that the activity order is in not fully consistent with the Pd dispersion as the activity of Pd/ZSM-5 $\left(T_{50}=224^{\circ} \mathrm{C}\right)$ is superior to that of Pd/MCM-48 $\left(T_{50}=245^{\circ} \mathrm{C}\right)$ although Pd $/ \mathrm{ZSM}-5$ 
possesses a lower Pd dispersion (Pd particles diameter: $3.07 \mathrm{~nm}$ ) (Fig. 7 and Table 1). Moreover, the specific surface area of Pd/ZSM$5\left(326.4 \mathrm{~m}^{2} / \mathrm{g}\right)$ is also smaller than that of Pd/MCM-48 $\left(1029 \mathrm{~m}^{2} / \mathrm{g}\right)$ (Table 2). Many researchers reported that Pd particles loaded on acidic supports were more easily oxidized than supported on the neutral or basic support as the acidic supports with electrophilic character resulted in the electron deficient on Pd atoms [10,12,14], and the acceleration of $\mathrm{Pd}^{0} \rightarrow \mathrm{Pd}^{2+}$ can also promote the catalytic process according to the Mars-van Krevelen model (the second step). As a consequence, we expect that the acidity and Pd dispersion have a synergetic effect on benzene catalytic oxidation, as the acidity of Pd/ZSM-5 (0.41 $\mathrm{mmol} \mathrm{NH}_{3} /$ g cat.) is much higher than that of Pd/MCM-48 (0.02 $\mathrm{mmol} \mathrm{NH}_{3} / \mathrm{g}$ cat.) (Table 3$)$. In conclusion, the superior catalytic activity of $\mathrm{Pd} / \mathrm{ZM}-x$ is a synergetic of the support acidity, the Pd dispersion, and the $\mathrm{CO}_{2}$ desorption capability.

\subsection{Thermal stability of the synthesized catalysts}

The used catalysts were characterized by $\mathrm{N}_{2}$ adsorption/desorption, XRD and TGA, as shown in Table 2, Figs. S1, S2 and S4. The XRD result reveals that the structure of the used catalysts is well preserved (Fig. S2). The specific surface area of all used composite catalysts has a small decrease, and the composite materials possess better catalytic stability than the MCM-48 (Table 1). According to the surface area changes before and after the catalytic reaction, the thermal stability order reduces as follows: $\mathrm{Pd} / \mathrm{ZSM}-5 \approx \mathrm{Pd} / \mathrm{ZM}-40>\mathrm{Pd} / \mathrm{ZM}-80>\mathrm{Pd} / \mathrm{ZM}-$ $20>\mathrm{Pd} / \mathrm{ZM}-160>\mathrm{Pd} / \mathrm{MCM}-48$ (Table 2 ). On the other hand, the catalytic test conditions, such as the formation of $\mathrm{H}_{2} \mathrm{O}$ during the reaction, may lead to a partial breakdown of the materials or a formation of coke on the supports. As is known, coke is able to deactivate the catalyst and thus reduce the catalytic activity. Fig. S4 shows that only an endothermic peak centered at around $80^{\circ} \mathrm{C}$ can be observed for all used samples due to the desorption of adsorbed water [42]. It is noteworthy that no mass loss can be found when the temperature is higher than $200^{\circ} \mathrm{C}$, indicating that no coke was formed on these catalysts.

\section{Conclusions}

In the present work, the ZSM-5/MCM-48 composite materials with various acid strength and enhanced thermal stability have been synthesized via a simple and reproducible crystallization process. At the same time, the $\mathrm{Pd} / \mathrm{ZM}-x$ composite catalysts were extensively characterized and their catalytic activities for benzene oxidation were also tested. The composite catalysts have a relatively high surface area and large pore diameter. In general, a higher $\mathrm{Si} / \mathrm{Al}$ molar ratio leads to a higher ZSM-5 content in the composite materials, and their acidity is much stronger than that of the pure MCM-48. Interestingly, the number of strong acid sites increases with the Si/Al molar ratio falling, which seems to result in a better Pd dispersion on these composite materials. All Pd-impregnated composite materials act as active catalysts for benzene oxidation where both $\mathrm{Pd}^{0}$ and $\mathrm{Pd}^{2+}$ are responsible for the reactions, and benzene catalytic oxidation can be explained by the Mars-van Krevelen model. All the composite catalysts demonstrate improved catalytic activity compared to Pd/MCM-48, in particular, Pd/ZM-40 shows the most superior catalytic activity, reducing the $90 \%$ Benzene conversion temperature from $292^{\circ} \mathrm{C}(\mathrm{Pd} / \mathrm{MCM}-48)$ to $204^{\circ} \mathrm{C}$. Their superior catalytic activity can be explained in terms of the synergetic of support acidity, the Pd dispersion and the $\mathrm{CO}_{2}$ desorption capability. In general, these novel Pd-loaded composite catalysts are promising materials for eliminating VOCs, and probably have other potential application in adsorption and separation.

\section{Acknowledgements}

National Basic Research Program of China (no. 2010CB732300), the National High Technology Research and Development Program of China (no. 2006AA06A310), and National Science Fund for Distinguished Young Scholars (no. 20725723) are gratefully acknowledged.

\section{Appendix A. Supplementary data}

Supplementary data associated with this article can be found, in the online version, at doi:10.1016/j.apcatb.2010.03.005.

\section{References}

[1] N. Li, F. Gaillard, Appl. Catal. B: Environ. 88 (2009) 152-159.

[2] S.F. Zuo, Q.Q. Huang, J. Li, R.X. Zhou, Appl. Catal. B: Environ. 91 (2009) 204-209.

[3] J.J. Li, X.Y. Xu, Z. Jiang, Z.P. Hao, C. Hu, Environ. Sci. Technol. 39 (2005) 1319-1323.

[4] M. Guillemot, J. Mijoin, S. Mignard, P. Magnoux, Appl. Catal. B: Environ. 75 (2007) 249-255

[5] W.G. Shim, J.W. Lee, S.C. Kim, Appl. Catal. B: Environ. 84 (2008) 133-141.

[6] S.C. Kim, W.G. Shim, Appl. Catal. B: Environ. 92 (2009) 429-436.

[7] T. Garcia, B. Solsona, D.M. Murphy, K.L. Antcliff, S.H. Taylor, J. Catal. 229 (2005) $1-11$.

[8] T. Garcia, B. Solsona, D. Cazorla-Amoros, A. Linares-Solano, S.H. Tayor, Appl. Catal. B: Environ. 62 (2006) 66-76.

[9] P. Papaefthimiou, T. Ioannides, X.E. Verykios, Appl. Catal. B: Environ. 13 (1997) $175-184$.

[10] K. Okumura, T. Kobayashi, H. Tanaka, M. Niwa, Appl. Catal. B: Environ 44 (2003) 325-331.

[11] H.L. Tidahy, S. Siffert, J.-F. Lamonier, E.A. Zhilinskaya, A. Aboukaïs, Z.-Y. Yuan, A. Vantomme, B.-L. Su, X. Canet, G. De Weireld, M. Frère, T.B. N'Guyen, J.-M. Giaudon, G. Leclercq, Appl. Catal. A: Gen. 310 (2006) 61-69.

[12] K. Muto, N. Katada, M. Niwa, Appl. Catal. A: Gen 134 (1996) 203-215.

[13] K. Okumura, J. Amano, N. Yasunobu, M. Niwa, J. Phys. Chem. B 104 (2000) 1050-1057.

[14] K. Okumura, S. Matsumoto, N. Nishiaki, M. Niwa, Appl. Catal. B: Environ. 40 (2003) 151-159.

[15] T. Tsoncheva, L. Ivanova, J. Rosenholm, M. Linden, Appl. Catal. B: Environ. 89 (2009) 365-374

[16] K.J. Kim, H.G. Ahn, Appl. Catal. B: Environ. 91 (2009) 308-318.

[17] A.M. Venezia, G. Di Carlo, G. Pantaleo, L.F. Liotta, G. Melaet, N. Kruse, Appl. Catal. B: Environ. 88 (2009) 430-437.

[18] F.N. Aguero, B.P. Barbero, L. Gambaro, L.E. Cadus, Appl. Catal. B: Environ. 91 (2009) 108-112.

[19] C.Y. Ma, B.J. Dou, J.J. Li, J. Cheng, Q. Hu, Z.P. Hao, S.Z. Qiao, Appl. Catal. B: Environ. 92 (2009) 202-208.

[20] Y.Q. Song, X.X. Zhu, Y. Song, Q.X. Wang, L.Y. Xu, Appl. Catal. A: Gen. 302 (2006) 69-77.

[21] A. Corma, Chem. Rev. 97 (1997) 2373-2420.

[22] J.Y. Ying, C.P. Mehnert, M.S. Wong, Angew. Chem., Int. Ed. 38 (1999) 56-77.

[23] J.S. Beck, J.C. Vartuli, W.J. Roth, M.E. Leonowicz, C.T. Kresge, K.D. Schmitt, C.T.W. Chu, D.H. Olson, E.W. Sheppard, S.B. McCullen, J.B. Higgins, J.L. Schlenkert, J. Am. Chem. Soc. 114 (1992) 10834-10843

[24] A. Karlsson, M. Stocker, R. Schmidt, Microporous Mesoporous Mater. 27 (1999) $181-192$.

[25] K.R. Kloetstra, H. van Bekkum, J.C. Jansen, Chem. Commun. 23 (1997) 2281-2282.

[26] Y. Liu, W. Zhang, T.J. Pinnavaia, J. Am. Chem. Soc. 122 (2000) 8791-8792.

[27] Y. Liu, W. Zhang, T.J. Pinnavaia, Angew. Chem., Int. Ed. 40 (2001) 1255-1258.

[28] W. Guo, C. Xiong, L. Huang, Q. Li, J. Mater. Chem. 11 (2001) 1886-1890.

[29] Z. Zhang, Y. Han, L. Zhu, R. Wang, Y. Yu, S. Qiu, D. Zhao, F.S. Xiao, Angew. Chem., Int. Ed. 40 (2001) 1258-1262.

[30] F.S. Xiao, Y. Han, Y. Yu, X. Meng, M. Yang, S. Wu, J. Am. Chem. Soc. 124 (2002) 888-889.

[31] Y.D. Xia, R. Mokaya, J. Mater. Chem. 14 (2004) 3427-3435.

[32] D.T. On, S. Kaliaguine, Angew. Chem., Int. Ed. 40 (2001) 3248-3251.

[33] D.T. On, S. Kaliaguine, Angew. Chem., Int. Ed. 41 (2002) 1036-1040.

[34] Y. Li, J. Shi, Z. Hua, H. Chen, M. Ruan, D. Yan, Nano Lett. 3 (2003) 609-612.

[35] P. Prokešová, S. Mintova, J. Čejka, T. Bein, Microporous Mesoporous Mater. 64 (2003) 165-174

[36] Y.D. Xia, R. Mokaya, J. Mater. Chem. 14 (2004) 863-870.

[37] C. He, J.J. Li, J. Cheng, L.D. Li, P. Li, Z.P. Hao, Z.P. Xu, Ind. Eng. Chem. Res. 48 (2009) 6930-6936.

[38] N. Krishnankutty, J. Li, M.A. Vannice, Appl. Catal. A: Gen. 173 (1998) 137-144

[39] J.J. Li, Z. Jiang, Z.P. Hao, X.Y. Xu, Y.H. Zhuang, J. Mol. Catal. A: Chem. 225 (2005) 173-179.

[40] C.T. Kresge, M.E. Leonowicz, W.J. Roth, J.C. Vartuli, J.S. Beck, Nature 359 (1992) 710-712.

[41] W.H. Zhang, J.L. Shi, L.Z. Wang, D.S. Yan, Chem. Mater. 12 (2000) 1408-1413. 
[42] C.J. Van Oers, W.J.J. Stevens, E. Bruijn, M. Mertens, O.I. Lebedev, G. Van Tendeloo, V. Meynen, P. Cool, Micropor. Mesopor. Mater. 120 (2009) 29-34.

[43] Y.H. Zhang, Y.C. Liu, Y.X. Li, Appl. Catal. A: Gen. 345 (2008) 73-79.

[44] V.N. Shetti, J. Kim, R. Srivastava, M. Choi, R. Ryoo, J. Catal. 254 (2008) 296-303.

[45] J. Jiao, S. Altwasser, W. Wang, J. Weitkamp, M. Hunger, J. Phys. Chem. B 108 (2004) 14305-14310.

[46] P.T. Tanev, T.J. Pinnavaia, Science 267 (1995) 865-867.

[47] M.A. Camblor, A. Corma, S. Valencia, Microporous Mesoporous Mater. 25 (1998) 59-74.

[48] R.S.G. Ferreira, P.G.P. de Oliveira, F.B. Noronha, Appl. Catal. B: Environ. 50 (2004) $243-249$.

[49] S.F. Zuo, R.X. Zhou, Microporous Mesoporous Mater. 113 (2008) 472480

[50] H.S. Kim, T.W. Kim, H.L. Koh, S.H. Lee, B.R. Min, Appl. Catal. A: Gen. 280 (2005) 125-131.
[51] S. Lambert, C. Cellier, E.M. Gaigneaux, J.-P. Pirard, B. Heinrichs, Catal. Commun. 8 (2007) 1244-1248.

[52] P. Sangeetha, K. Shanthi, K.S. Rama Rao, B. Viswanathan, P. Selvam, Appl. Catal. A: Gen. 353 (2009) 160-165.

[53] A.H. Padmasri, A. Venugopal, J. Krishnamurthy, K.S. Rama Rao, P. Kanta Rao, J. Phys. Chem. B 106 (2002) 1024-1031.

[54] F.X. Yin, S.F. Ji, P.Y. Wu, F.Z. Zhao, C.Y. Li, J. Catal. 257 (2008) 108-116

[55] L.S. Feio, J.C. Escritori, F.B. Noronha, C.E. Hori, Catt. Lett. 120 (2008) 229-235.

[56] C. Leitenburg, A. Trovarelli, J. Llorca, F. Cavani, G. Bini, Appl. Catal. A: Gen. 139 (1996) 161-173.

[57] A. Aranzabal, J.A. González-Marcos, J.L. Ayastuy, J.R. González-Velasco, Chem. Eng. Sci. 61 (2006) 3564-3576.

[58] L.M. Gomez-Sainero, X.L. Seoane, J.L.G. Fierro, A. Arcoya, J. Catal. 209 (2002) 279-288.

[59] M. Bonarowska, J. Pielaszek, V.A. Semikolenov, Z. Karpinski, J. Catal. 209 (2002) 528-538. 